\title{
Determinants of Youth Unemployment: The Case of Areka Town, Wolaita Zone, Ethiopia
}

\author{
Loha Menta ${ }^{1} \quad$ Tekle Leza ${ }^{2}$ \\ 1.Masters in Rural Department and planning, Department of Rural Development and Agricultural Extension, \\ College of Agriculture, Wolaita Sodo University, P.O.Box, 138, Wolaita Sodo, Ethiopia \\ 2.Vice President for Business and Development, $\mathrm{PhD}$ in Livelihood and Poverty Reduction, Department of Rural \\ Development and Agricultural Extension, Wolaita Sodo University, P.O.Box, 138, Wolaita Sodo, Ethiopia
}

\begin{abstract}
Presently days, the development of youth unemployment is one of the basic financial issues confronting Ethiopia by and large and the study area specifically. Nonetheless, this isn't thought about the elements fueling youth unemployment in the examination zone. Considering this issue, this investigation is directed with destinations of distinguishing factors influencing youth unemployment, in Areka town of Wolaita Zone, Ethiopia. The research focused on the quantitative data collection through household survey. The Multi-stage sampling design was used. In the $1^{\text {st }}$ stage, Areka town was chosen purposively and in the $2^{\text {nd }}$ stage 120 rural youths (18-34 age groups) were selected from Four Kebeles by using simple random sampling method. The primary data were collected from the 120 youths with the help of the constructed Interview schedule. The descriptive and inferential statistics along with Binary logit model were used to analyze the data. Among all the respondents, 20.83 percent were employed, while 79.17 percent were unemployed at the hour of the examination. The econometric model investigation showed that Household Income, Job preference, Access to credit, Access to training and Cooperative membership have significant impact on Youth unemployment. Among this Job preference at 1\% significant level, and the Household Income, Access to Credit, Access to training and Cooperative Membership were at 5\% significant level. Based on the discoveries of the examination: Provide accommodative credit access, improve wages of individual families and certain regions ought to be utilized specifically.
\end{abstract}

Keywords: Unemployment status, Youth, Binary Logit Model, Inferential statistics, Job opportunities, Household Income, Credit, Training

DOI: $10.7176 / \mathrm{JESD} / 11-17-05$

Publication date:September $30^{\text {th }} 2020$

\section{Introduction}

\subsection{Background}

Unemployment is one of the primary difficulties of the advanced time in both in the developed and developing countries in the world. Particularly adolescents, which the United Nations characterizes as, those between the ages of 15-24, are more influenced by joblessness. Youngsters are more vulnerable against lack of experience, social networks or different capabilities that would make them hard to track down business. In many regions' youth were almost three times more likely to be unemployed than adults (ILO, 2012). Global unemployment levels and rates are relied upon to stay high temporarily, as the worldwide labor force keeps on developing. Specifically, the worldwide joblessness rate is relied upon to rise humbly in 2017 , to $5.8 \%$ from $5.7 \%$ in 2016 - speaking to 3.4 million more jobless individuals universally that carrying complete joblessness to a little more than 201 million of every 2017 (ILO, 2017).

Youth are among the hugest threatening essentialness and asset a nation can need to build its social economic development. Besides, they are huge in number; they are vigorous, fearless and produce novel thoughts that can make changes to the social economic development if they are well organized and participated in economic activities of the country. Independent of such standing youth have been confronted with numerous challenges one of them being joblessness issue. Youth unemployment is among the key issues that confronting both developed and developing countries on the planet (LFS, 2013).

Youth unemployment breeds disillusionment, misery, and gloom. These conditions are bound to bring about youth taking part in hazardous and dangerous conduct. The results of youth's hazardous conduct influence their own wellbeing, their families' networks and the country on the loose. As it were, they may be Unproductive, they feel a sense of hopelessness, and be at great risk for drug and alcohol addiction delinquency and engaging in crime. This may eventually additionally prompt social agitation and civil disobedience. (TaYa, 2013).

Joblessness in Ethiopia is to a greater extent an issue of metropolitan youth than that of rural. As indicated by Ethiopian labor force survey report, the unemployment rates of urban youth at country level were $22.9 \%$ while for rural youth stayed at $3.1 \%$ only. (LFS, 2013). A recent Ethiopian Population survey shows that vast majority of the Ethiopia's populace is youthful with the young and children populace alone representing $40.6 \%$ the absolute populace in 2011(CSA, 2012).

The difficulties looked in Ethiopia by youngsters in labor market incorporate joblessness, low paid, low 
skilled jobs without possibilities for professional success and often working under poor informal economic activity. Youth work moves contrasts starting with one nation then onto the next and a few nations face more noteworthy difficulties than others. In view of the above realities, this particular research study has attempted to analyze the socio-economic and demographic determinants of urban and youth unemployment in Areka Town in Wolaita Zone, Ethiopia.

\subsection{Statement of the Problem}

A high level of unemployment is one of the critical socio-economic problems facing Ethiopia while the labor grows with an increasing proportion of youth. Employment growth is inadequate to absorb labor market entrants. As a result, youth are especially affected by unemployment. Moreover, young people are more likely to be employed in jobs of low quality. Unemployed, working long hours for low wages, engaged in dangerous work receive only short term and/ or informal employment arrangement (TaYa, 2013).

Like many other developing countries unemployment has been one of the major problems in Ethiopia. The excessive rate of unemployment negatively impacts on economy which causes unstable economic conditions. This is troublesome because when workers are unemployed, there is an under-utilization of resources. So, the total production of a country is less than its potential level of output because resources are not fully utilized in these countries (Maqbool et. al., 2013)

All these lead to the erosion of a healthy society (Maqbool et al., 2013). Unemployment is of a special concern for Ethiopians and has a wider implication for the youth in addition to leading their life as expected to help parents and extended families (Shumet, 2011). According to a survey in 55 urban areas, unemployment was estimated at $41.3 \%$ and the incidence of youth unemployment was $45.5 \%$ and $35.7 \%$ for females and males respectively (Alemnew, 2014).

Areka town, like other towns of the country also manifests the problem of youth unemployment. As Wolaita Zone Town development head job creation coordinator 2018 yearly report zonal numbers of unemployed urban youths are Male 29443,Female 13117, and total 42560 Among this number youth under the age of 18-34 found in Areka town: Male 2504 Female 2329 and total 4833 from this, $1^{\text {st }}$ degree holder -Male 175 Female 154 and total 359; diploma -Male 246, Female 249 and total 492; from $9^{\text {th }}$ and $12^{\text {th }}$ grade complete-Male 1142 Female 1067 and total 2209; from 1 - 8 grade complete Male 849 Female 728 and total 1577, Not attended school-Male 92 Female 134and total 226 as the data taken from Areka Town Job Creation and Food Security Office, Boloso Sore District, (2017). This shows that how much challenges for youth unemployment and specific factors that affect the opportunities of youth employment in the Areka Town.

Many young people in Areka town are trapped in a very difficult situation of unemployment which has always caused them untold suffering and living under poor conditions. Government and other stakeholders like NGOs and private sector have attempted to put in place opportunities like in provision of capital through micro finance institutions but even the educated have remained unemployed and many governmental strategies to address the youth unemployment predicament have not had expected success. This situation has been attributed to general lack of skills by the youth because many have not acquired the required skills to secure jobs in the formal sector and the high population growth rates. Besides that, many youths blame lack of capital yet they are willing to do business and improve their living standards. Even though urban unemployment is a critical problem, but no study has been conducted in the study area prior to this study. This suggests a need to carry out through studies into the situation of youths and try to address their difficult situation if anything is to be done to help them out and which is the main aim for this study.

Even though few studies are conducted on youth unemployment in Ethiopia (Asalfew 2011; Tegegne, 2011; Amanuel,2016; Dejene et. al., 2016;Alemnew, 2014), the results of these studies contradict each other which needs further study based on the specific socio-economic situation of the study area. Hence, this is why the present study focusing on determinants of youth unemployment to fill the knowledge gap, Besides, the study is meant to generate empirical evidences and accordingly better understanding of development actors in their future planning and promotion of youth unemployment.

\section{Methodology}

\subsection{Sampling Techniques}

Multi-stage sampling technique was employed in the research study. At the first stage, Areka town was selected purposively because of the Youth groups are highly dominant Kebeles and catchment area of the Wolaita Sodo University. In the second stage four Kebeles were selected by using Simple random sampling was employed to determine the sample size from each Kebele and finally 120 households were selected by using Systematic random sampling.

\subsection{Sample Size Determination}

The sample size was determined by using simplified formula provided by (Yamane, 1967). Based on simplified 
formula 120 youth were determined.

$$
\mathrm{n}=\frac{N}{1+(N)\left(e^{2}\right)} \quad \mathrm{n}=\frac{4833}{1+(4833)\left(0.09^{2}\right)}=120
$$

Where $\mathrm{n}$ is the sample size, $\mathrm{N}$ is total unemployment in the study area and $\mathrm{e}$ is the error term. Confidence level of $90 \%$ is used to ensure a more accurate result from the sample.

\subsection{Data Collection Tools}

Both primary and secondary data sources were used. The primary data were collected using Interview schedule that cover Demographic, Economic, Institutional and Psychological factors. The Interview schedule was used to gather information from the youth respondent by translating the Interview schedule in to Amharic for easy of understanding. The well trained two enumerators were recruited from the study area. The pre-testing study was conducted with 12 households before conducting the face to face Interview and then the questions were adjusted in the interview schedule in order to maintain the validity or reliability of the research.

Table1. Sample size determination status by the Kebeles

\begin{tabular}{lllll}
\hline Sample Kebeles & \multicolumn{2}{l}{ Total number } & Sample size & Remark \\
\cline { 2 - 4 } & Unemployed & Employed & Unemployed & Employed \\
\cline { 2 - 4 } & & & & \\
Kebele 01 & 1278 & 371 & 20 & 5 \\
Kebele 02 & 1621 & 427 & 27 & 5 \\
Kebele O3 & 1179 & 351 & 31 & 7 \\
Kebele 04 & 755 & 271 & 17 & 8 \\
\hline Total & $\mathbf{4 8 3 3}$ & $\mathbf{1 4 2 0}$ & $\mathbf{9 5}$ & $\mathbf{2 5}$ \\
\hline
\end{tabular}

Source: Areka Town Job Creation and Food Security Office, Boloso Sore District, 2017

\subsection{Method of Data Analysis}

There are two categories of data analysis methods namely descriptive statistics and econometrics models were used to analyze the data collected from the sample in the study area. Descriptive statistics methods of the data analysis used refer to mean, percentage, and standard deviation. Inferential statistics Chi-square and t-test were used in the process of comparing socio-economic, demographic, psychological, institutional and informational characteristics of the unemployed youths in the study area. Methodological framework and selection of econometric model depend on objectives to be achieved and hypothesis to be verified. Based on the fact, Binary logit model was used to analyze hypothesized variables.

\subsection{Specifications of Variables and Hypothesis}

In this study, the dependent variable and 12 explanatory or independent variables are specified to be estimated in the model and draw some important statistical conclusion on unemployment status.

\subsubsection{The Dependent Variable}

Y-Youth unemployment (UNEMPLOYMENT) (Y)-this was the dependent variable, and has dichotomous nature. Thus, it is represented by 1 if Unemployed youths and 0 Employed youths. Youth constitutes individuals who found between lower ages limits of 18 years old and 34 years old of above age limit because there is age restriction to use different kinds of rights. (Nganwa et al., 2015) mentions unemployed youth as group young people's with different backgrounds who seek and are able to work but unable to find or start any work.

Table 2: Independent Variables and Expected Signs

\begin{tabular}{lllc}
\hline Variable Code & Variable Type & \multicolumn{1}{c}{ Variable Definition } & Sign of Variables \\
\hline AGE & Continuous & Age of the youth & $(+)$ \\
EDUC & Categorical & Youth education status & $(-)$ \\
MARIT & Dummy & Marital status of youth & $(-)$ \\
SEX & Dummy & Sex of the youth & $(-)$ \\
INCOME & Continuous & Income of youth family & $(+)$ \\
JOBPR & Categorical & Youth job selection & $(+)$ \\
CREDIT & Dummy & Access to credit & $(-)$ \\
TRAIN & Dummy & Access of ATVT training received & $(-)$ \\
MEDIA & Dummy & Access to media & $(+)$ \\
COOPM & Dummy & Membership of youth & $(+)$ \\
MIGRA & Dummy & Status of Youth migration & $(+)$ \\
PERMIS & Dummy & Working area to the business & $(+)$ \\
\hline
\end{tabular}

\section{Results and Discussion}

This part dealt with the results of both descriptive statistics and regression outputs of the empirical model. The 
analysis was based on the objectives of the study. There are different methods of assessing the association and mean difference between two variables. Pearson Chi-square test and t-test are one way for examining relationship and mean difference. Chi- square measures the degree of association between a given independent variable where as the t-test reveals the mean differences, variable keeping the effect of the other variables remains constant (Montgomery and Peck, 1992).

\section{Descriptive Analysis}

Unemployment Status of Respondents: The survey result revealed that, out of 120 sample households included in the survey 79.17 percent were unemployed youths and 20.83 percent were employed youths.

Table 3: Unemployment Status of Respondents

\begin{tabular}{lll}
\hline Category & Frequency & Percent \\
\hline Unemployed & 95 & 79.17 \\
Employed & 25 & 20.83 \\
\hline Total & $\mathbf{1 2 0}$ & $\mathbf{1 0 0 . 0 0}$ \\
\hline
\end{tabular}

Source: Source Field survey 2019

Age of respondents (AGE): Age of the youths of respondents was one of the demographic factor determining urban youth unemployment. The survey result reveals that, the total mean age of the sample Youths was 24.93 years with the standard deviation of 3.46. The mean age value of the employed youths was 23.86 years with the standard deviation of 3.159. On the other hand, the mean age of the unemployed youths was 25.24 years with the standard deviation of 3.96. The t-test shows that mean difference between age and youth unemployment had insignificant. $(\mathrm{t}=-0.817, \mathrm{P}=0.366)$ Table-4

Household income (HHI): Household income of the respondents was one of the economic factors determining urban youth unemployment. The employed and unemployed household generate on average annual income of Birr 1048 and 471 with the standard deviations of 308 and 392 birr respectively. The independent t-test between employed and unemployed shows statistically significant mean difference at less than one percent probability level $(\mathrm{t}=2.779, \mathrm{p}=0.000)$. Table 4

Sex of respondents (SEX): Sex of the youths of respondents was one of demographic factor determining urban youth unemployment. The survey result reveals that, out of 120 sample youths included in the survey 43(35.8\%) respondents were female and $77(64.2 \%)$ were male. The relationship between sex and youth employment status illustrates that among 43 females households included in the sample, 8(32\%) were employed and 35(36.9\%) unemployed while 77(64.2) percent of males among 17(68\%) percent were employed and 60(63.1\%) were unemployed. This shows that female unemployment is higher than male unemployment. This result shows that male-headed households are more engaged in the paid employment than female-headed households. This implies that most of women head are demanded in different workloads including social issues and they are not able to actively participate in paid work. The $\chi 2$ test indicates a statistically insignificant association between sex and employment status. $(\chi 2=6.5, \mathrm{p}=0.001)$

Marital status (MARIT): Marital status of respondents is one of demographic factor determining urban youth unemployment. The result shows that from total 120 respondents $93(77.5 \%)$ of respondents were single out of these $17(68 \%)$ were employed and $76(80 \%)$ were unemployed. Whereas $27(22.5 \%)$ of respondents were married, out of these $8(32 \%)$ were employed and the remaining $19(20 \%)$ were unemployed. The $\chi 2$-test shows the absence of significant mean difference between the two groups and also it illustrated as there is insignificant relationship between employment statuses and Marital status of the respondents. $(\chi 2=1.897, \mathrm{P}=0.168)$. Table 5

Educational level (EDUC): Educational level was one of the factors determining urban youth unemployment. The education status of urban youth enables them to acquire knowledge and skill and this, increases their productivity. Comparison between participants and non- participants respect to education was statistically significant mean difference at less than $5 \%$ probability level. The result shows that from total 120 respondents $6(5 \%)$ youths responded that their educational level was Primary level and out of these $6(6.3 \%)$ were unemployed. Whereas $12(10 \%)$ were responded as their education level was secondary, out of these $12(12.6 \%)$ were unemployed. 21(17.5\%) respondents education level is Certificate and those are unemployed and $43(35.8 \%)$ educational level Diploma, out of these 11(44\%)were employed and 32(33.7\%) were unemployed. The remaining $38(31.7 \%)$ respondents were Degree and above out of these $14(56 \%)$ were employed and $24(25.3 \%)$ were unemployed. The finding clearly shows that when education level increases the unemployment decreases this is due to the fact that when people get educated they may acquire extra knowledge that can capable them to obtain better opportunity for getting job. The $\chi 2$ - test indicates a statistically in significant association between education and employment status $(\chi 2=1.839, \mathrm{p}=0.175)$. Table 5

Work Premises (PERMIS): Working premises was one of the important determinants of youth unemployment. It plays central role for business start up and transaction. Finding reveals that $14(56 \%)$ of employed and 3(3.2\%) of unemployment owned working premises while 11(44\%) of employed and 92(96.8) of unemployed didn't owned working premises. Majority of employed and unemployed youths didn't have working premises for business. The 
$\chi 2$-test shows insignificant association between employed status and unemployed status with working premises. $(\chi 2=0.045, p=0.832)$

Migration (MIGRA): Migration was one of the determining factors of youth unemployment. The findings revealed that from total 120 respondents $25(100 \%)$ have no migrate and $82(86.3 \%)$ respondents had no migrate to find job. From those unemployed youths $13(10.8 \%)$ had migrate to find job. Majority of the respondents mentioned that they have no migrate which is factor for low rate of youth unemployment. The $\chi 2$ - test shows that statistically insignificant association between migration and youth unemployment status $\left(\chi^{2}=1.920, p=0.648\right)$.

Job Preferences (JOBP): Job preference was one of the factors determining youth unemployment. As shown in Table 5, the finding revealed that from total 120 respondents $8(9.4 \%)$ of unemployed youths responded that they prefer paid employment (private or government institution, Whereas $23(21 \%)$ of respondents agreed that they prefer self-employment, out of these $7(35.7 \%)$ were employed and $16(16.7 \%)$ were unemployed. The remaining $89(71.8 \%)$ of respondents were responded that they are preparing any available job, out of these $18(64.3 \%)$ were employed and 71(74\%) were unemployed. The $\chi 2$ - test shows that the association between Job preference and unemployment status significant at less than $5 \%$ probability level $(\chi 2=6.469, \mathrm{p}=0.001)$.

Access to Training (TRAIN): Training was one of the factors determining urban youth unemployment. The result shows that from total 120 respondents $17(68 \%)$ employed youths have got training and $8(32 \%)$ employed youths hadn't got training. In the other hand out of 95 unemployed youths 3(3.2\%) unemployed youths have got training while 92(96.8\%) unemployed youths have not got training. The result shows that youths who got training obtain better job opportunity than those who have not got training. This finding was consistent with the similar study of with that of (Serneels, 2007). The $\chi 2$-test shows significant association between training and unemployed status with access to training at less than $1 \%$ probability level. $(\chi 2=7.279, p=0.007)$ Table 5

Cooperative Membership (COOPM): Membership of Cooperatives was one of the factors determining youth unemployment. The respondents were asked to respond that do they have good participation in the cooperatives or not. The result shows that from total 120 respondents $21(84 \%)$ employed and $89(93.7 \%)$ unemployed youths responded that they have good participation in cooperatives, in the other hand $4(16 \%)$ employed and $6(6.3 \%)$ unemployed youths were responded that they have no participation in cooperatives. The result of this study shows that youths who have good participation in cooperatives were better chance to obtain job opportunity. The $\chi 2$-test shows significant association between employed status and unemployed status with cooperative membership at less than $1 \%$ probability level. $(\chi 2=7.002, p=0.000)$

Access to Credit (CREDIT): Access to credit was one of the factors determining youth unemployment. The study revealed that from total 120 respondents $19(76 \%)$ employed and 64(67.4\%) unemployed youths have access to credit while 6(24\%) employed and 31(32.6\%) unemployed youths were have no access to credit. The result shows those youths who have access to credit were better chance to obtain job opportunity. The $\chi 2$ test shows significant association between credit access and unemployed status with access to credit at less than $1 \%$ probability level. $\left(\chi 2^{=} 7.240, \mathrm{p}=0.003\right)$.

Access to Media (MEDIA): Access to media was one of the factors determining youth unemployment. Out of the sampled employment status 22(88\%) employed and 78(82.1\%) were unemployed youths responded that they had accessed media, whereas, the rest $3(12 \%)$ employed youths and $17(17.9 \%)$ unemployed youths did not access media. The $\chi 2$ - test shows that statistically insignificant association between acce 3 ss to media and youth unemployment status $(\chi 2=2.15, \mathrm{p}=0.142)$. Table 5

Table 4: Statistical Summary of Sampled Employed and Unemployed on Continuous Variables

\begin{tabular}{|l|l|c|c|c|}
\hline \multirow{2}{*}{ Variables } & Employed (n=25) & Unemployed (n=95) & Total (n= 120) & \multirow{2}{*}{ t-value } \\
\cline { 2 - 4 } & Mean (Std. Dev) & Mean (Std. Dev) & Mean (SD ) & \\
\hline AGE & $23.86(3.159)$ & $25.24(3.96)$ & $24.93(3.46)$ & 0.817 \\
\hline HHI & $1040(308)$ & $302(214)$ & $471(391)$ & $0.000^{* * *}$ \\
\hline
\end{tabular}

Note: "**” and "***”, denote significance at 5, $1 \%$ levels respectively 
Table 5: Statistical Summary of sampled Youth Employed and Unemployed on Dichotomous Variables

\begin{tabular}{|c|c|c|c|c|c|c|c|c|}
\hline \multirow{3}{*}{ Variables } & \multirow{3}{*}{ Description } & \multicolumn{6}{|c|}{ Employment Status } & \multirow{2}{*}{$\begin{array}{l}\chi^{2} \\
\text { value }\end{array}$} \\
\hline & & \multicolumn{2}{|c|}{ Employed $(n=25)$} & \multicolumn{2}{|c|}{ Unemployed $(n=95)$} & \multicolumn{2}{|c|}{ Total $(n=120)$} & \\
\hline & & No. & $\%$ & No. & $\%$ & No & $\%$ & \multirow{3}{*}{$0.001 * * *$} \\
\hline \multirow[t]{2}{*}{ SEX } & Male & 17 & 68 & 60 & 63.1 & 77 & 64.2 & \\
\hline & Female & 8 & 32 & 35 & 36.9 & 43 & 35.8 & \\
\hline \multirow[t]{3}{*}{ MARIT } & Single & 17 & 68 & 76 & 80 & 93 & 77.5 & \multirow[t]{3}{*}{0.168} \\
\hline & Married & 8 & 32 & 19 & 20 & 27 & 22.5 & \\
\hline & Divorced & - & - & - & - & - & - & \\
\hline \multirow[t]{4}{*}{ EDUC } & Primary & - & - & 6 & 6.3 & 6 & 5 & \multirow[t]{4}{*}{0.175} \\
\hline & Secondary & - & - & 12 & 12.6 & 12 & 10 & \\
\hline & Certificate & - & - & 21 & 22.1 & 21 & 17.5 & \\
\hline & Degree\& above & 14 & 56 & 24 & 25.3 & 38 & 31.7 & \\
\hline \multirow[t]{2}{*}{ PERMIS } & Yes & Yes & 14 & 56 & 3 & 3.2 & 17 & \multirow[t]{2}{*}{0.832} \\
\hline & No & No & 11 & 44 & 92 & 96.8 & 103 & \\
\hline \multirow[t]{2}{*}{ MIGRA } & Yes & - & - & 13 & 13.7 & 13 & 10.8 & 0.648 \\
\hline & No & 25 & 100 & 82 & 86.3 & 107 & 89.2 & \multirow{3}{*}{$0.007 * * *$} \\
\hline \multirow[t]{2}{*}{ TRAIN } & Yes & 17 & 68 & 3 & 3.2 & 20 & 16.7 & \\
\hline & No & 8 & 32 & 92 & 96.8 & 100 & 83.3 & \\
\hline \multirow[t]{2}{*}{ CREDIT } & YES & Yes & 19 & 76 & 64 & 67.4 & 83 & \multirow[t]{2}{*}{$0.003 * * *$} \\
\hline & No & No & 6 & 24 & 31 & 32.6 & 37 & \\
\hline \multirow[t]{2}{*}{ COOPM } & Yes & 21 & 84 & 89 & 93.7 & 110 & 91.7 & \multirow[t]{2}{*}{$0.000 * * *$} \\
\hline & No & 4 & 16 & 6 & 6.3 & 10 & 8.3 & \\
\hline \multirow[t]{2}{*}{ MEDIA } & Yes & 22 & 88 & 78 & 82.1 & 100 & 83.3 & \multirow[t]{2}{*}{0.142} \\
\hline & No & 3 & 12 & 17 & 17.9 & 20 & 16.7 & \\
\hline \multirow{3}{*}{ JOBP } & Paid Employ & - & - & 8 & 9.4 & 8 & 7.3 & \multirow{3}{*}{$0.001 * * *$} \\
\hline & Self-employ & 7 & 35.7 & 16 & 16.7 & 23 & 21.0 & \\
\hline & Any available & 18 & 64.3 & 71 & 74.0 & 89 & 71.8 & \\
\hline
\end{tabular}

Note: “*”, “***” represent significance at 1, 10 \% levels respectively Source: Field Survey, 2019

\subsection{Empirical Analysis}

Logistic regression model analysis was estimated to determine youth unemployment. The maximum likelihood method was employed to prefer to estimation of the logit model and statistically significant variables were identified in order to measure their relatives' importance on youth decision. The model likelihood ratio observation 120 , logit likelihood $=22.53, \mathrm{LR}\left(\mathrm{x}^{2}\right)=0.000 \mathrm{LR}\left(\mathrm{x}^{2} 13\right)=87.41$ showes that the model has strong explanatory power.

\section{Interpretation of Significant Variables using Odds Ratio}

Household income (HHI):-As expected, household income had negative and significant effect on youth unemployment at less than one percent probability level. Odd ratio reveals that one birr increase in income from the business leads to decrease the probability of unemployment status by a factor of 2.875 keeping all other variables remains constant. The possible justification of the result was when family income of youths increase they have opportunity to participate in different kinds of employment income generating activities. This finding is consistent with the finding of ILO (2004). Income of an individual's is very crucial to become increment of employment opportunity. As access to different income sources the rate of unemployment is decreased in odd ratio. In my study area case households income has significant effect on unemployment status of youths, currently the rate is decreasing due to increasing number of government projects on poverty reduction and unemployment . This made some better employment access to local youth.

Cooperative Membership (COOPM): As expected, the cooperative membership had positively influenced youth in the employment decisions market at less than $1 \%$ probability level. The odd ratio reveals that one unit increases participated by a cooperative membership by sample members leads to decrease the probability of unemployment status by a factor of 2.521 held all other variables held constant. The result implies youth who have better participation in cooperative membership it can give better chance to get employment easily. This finding is consistent with the finding of ILO (2004). That means youth people starts to participate in different local cooperative institutions the unemployment status some decreased than what they were before. When the youth are member kin different cooperatives they create different jobs.

Access to Training (TRAIN): Access to training is one of the independent variable which affects youth unemployment status. It affects unemployment status less than at 1\% probability level. The odd ratio reveals that being unemployed for youths who are not access to training is increase in 2.875 times than those who are get 
vocational training holding the effect of other factors constant. The result implies youths who are access to training it can give better chance to get employment. This finding is consistent with the finding (Serneels, 2007). In my study area access to training has significant effect on unemployment as seen from the table 6 result.

Access to Credit (CREDT):- As expected, access to credit was positive and significant which affects youth unemployment status less than at $1 \%$ probability level. The odd ratio reveals that one unit increases participation of a credit service by sample members leads to decrease the probability of unemployment status by a factor of 0.353 held all other variables are held constant. The result implies youth who have access to credit increase the opportunity to get job and decrease the probability of being unemployed. This result confirms the finding of (Mulugeta, 2013).

Job Preferences (JOBP):- Job preferences were positive and significant which affects youth unemployment status less than at $1 \%$ probability level. The odd ratio reveals that being unemployed for those respondents who preferred paid employment in the formal sectors was 1.301 times higher as compared to those who preferred any available job in the labor market holding the effect of other factors constant. The result implies educated youth prefer wage jobs in the formal sector and would prefer to remain unemployed until they get the type of job they prefer. This result confirms the finding of (Okojie, 2003). He found that job preferences affecting people in low income country, because people choose the better jobs to become economically active enough in their life.

Table 6: Binary Logit Regression Results

\begin{tabular}{lcccc}
\hline Explanatory Variables & Coefficient (B) & Wald statistics & Odds ratio & Significant level \\
\hline AGE & 0.079 & 0.817 & 1.082 & 0.366 \\
SEX & 0.013 & 0.001 & 1.014 & 0.973 \\
EDUC & 0.168 & 1.839 & 1.182 & 0.175 \\
MAR & -0.326 & 1.897 & 0.722 & 0.168 \\
COOPM & 0.925 & 7.002 & 2.521 & $0.008^{* * *}$ \\
JOBPR & 0.263 & 6.469 & 1.301 & $0.011^{* *}$ \\
HH INCOME & 0.578 & 7.279 & 2.875 & $0.008^{* * *}$ \\
MEDIA & -0.481 & 1.499 & 0.618 & 0.221 \\
TRAIN & 1.056 & 7.279 & 2.875 & $0.007 * * *$ \\
PREMISE & -0.31 & 0.045 & 0.970 & 0.832 \\
CREDIT & -1.042 & 7.240 & 0.353 & $0.007 * * *$ \\
MIGRA & -2.134 & 1.920 & 0.118 & 0.648 \\
\end{tabular}

Source: Own computation from survey data, 2019

$* * *, * *$ Significant at less than 1\%and 5\% probability level.

\section{Conclusion and Recommendations}

\subsection{Conclusion}

The goal of the investigation was to analyze determinants of youth unemployment on account of Areka Town, Wolaita Zone, Ethiopia. The primary data was collected from the respondents of employment status of the employed and unemployed youth members and secondary data information got from different offices, reports and investigated articles. Utilizing multi-stage sampling procedure 120 households were used met to accumulate information. Basically quantitative information was gathered utilizing Interview Schedule through interview where as qualitative data was gathered through informal interview.

The Descriptive and Econometric model was used to analyze determinants of youth unemployment in Areka Town, Wolaita Zone, Ethiopia. Additionally, the t-test and Chi-square data used to look at the mean difference and the variables relationship of critical factors individually. Additionally, the chi-square test uncovered that the discrete factors Job preference, access to credit, access to training and cooperative membership shows a significant relationship among employed and unemployed young people.

To recognize the factor influencing the households youth unemployment in the study area was utilized, the model outcome uncovered that among 12 explanatory variables incorporated the logit model 5 variables were discovered to be significant a less than $1 \%$ and $5 \%$ probability level. All the more explicitly the variables: household income versus Job preference, access to credit, access to training and cooperative membership. Among these noteworthy factors, Job preference and Cooperative membership were positively identified with youth unemployment where as Household income, access to credit, access to training were related to negatively to the dependent variables.

\subsection{Recommendations}

Youth unemployment or employment level choices are extraordinary significant for their critical positive effect on monetary turn of events. This has been seen from economic analysis and finding of this investigation. This outcome has significant arrangement suggestion to be suggested. 
- Household income is conversely related with youth unemployment and it underpins youths who are has a place with better pay family have better possibility of being employed and those young originated from poor family being jobless in the study area. Luck of the family income influences young people by empowering starting sparing capital and frustrates self-employment. Consequently, we suggest Poverty reduction methodologies should target explicit areas and explicit household's as more often than not poverty by its nature is individual focused instead of total.

Thusly, plans that can improve incomes of the individual households and certain territories ought to be employed specifically. Then again, young people who originated from less income (poor) families ought to specifically partake in looking for zero initial capital job opportunities. Anyway initial capital is expected to begin an occupation, the Government and other concerned bodies ought to be plan credits for jobless youths.

- Access to credit is likewise adversely associated with youth unemployment and it serves to builds the likelihood of being employed and diminishes the likelihood of being jobless in the study area. Most the jobless young people have access to credit yet absence of initial saving capital (with an earlier saving utilized as an essential to fit the bill for credit as group lending upsets credit access to the poor youths in the region. In any case, youth who originate from poor families discover group lending inconvenient to get to credit from MFI since they are dismissed from the group by better.

This as well as administration and absence of suitable job openings for work are not persuading the youths to utilize the credit. In this manner, accommodative credit policy ought to be utilized; implying that MFIs and other improvement organizations need to introduce the credit policies focusing on the poorest of the poor people. Occupation creating for youths ought to be appropriate and chosen by the active participation of the youths themselves just as government offices should convey dynamic help for youths in a brief timeframe.

- To emphasize more on practical training in each stage of learning. There is a need of underlining on practical training in each phase of learning whereby the Government should provide request to each educational institution to execute the utilization of this training framework as a method for showing the competent skills which can empower them to be utilized or independently employed and consequently decrease young people joblessness. To introduce entrepreneurship training in each college both nongovernment organization and government organizations ought to stress on enterprise training arrangement in every college to empower the students to get innovative skills which help them to employ themselves consequently diminish youth joblessness.

- Increasing the awareness of youth towards occupations. Preferring the jobs in the Government organizations improves the probability of being jobless. In this way, to improve the attention of the youth pushing the significance of self-employment by utilizing good examples; empowering youth to bring attitudinal change through instruction by sorting out mindfulness creation programs if vital.

- Supporting village/town level relationship to fortify: This upgrades an opportunity for better improvement for an employed activity in the study area. Consequently, strategies ought to be planned in such a manner to help and offer need to coming to the unbanked society. It has been plainly perceived that inclusion in village//town level saving and loan associations have a positive commitment to an individual's opportunity to participate in self-employment economic activity. This kind of microcredit additionally has an advantage of financing the business without the demands of the collateral. This improves an opportunity for better advancement for entrepreneurial activity in the study area. Hence, the policies must be planned in a way that supports the MFIs to come to the unbanked society.

- Furthermore, the investigation suggests that the concerned bodies should attempt to improve the living condition and the employment opportunities the local area to young people so as to decrease the idea of the migration. Since migrants are bound to be jobless in the metropolitan region and all in all can be a hotspot for metropolitan joblessness to rise. At last, endeavors ought to be made to expand the accessibility of initial working capital, the identification of gainful business regions, and the arrangement of viable practical training for urban youths to be occupied with their own business.

\section{References}

Alemnew Getnet (2014), Socio-economic \& Demographic Determinants of Graduate youths' unemployment: In the case of Debre Markos town, Amhara Regional State, University of Gonder.

Amanuel Disassa Abshoko (2016), Determinants of Youth Unemployment; Evidence from Ethiopia, Global Journal of Human-Social Science: An Arts \& Humanities - Psychology Volume 16, ISSN: 2249-460x \& Print ISSN: 0975-587X

Areka Town Job Creation and Food Security Office, Boloso Sore District, Wolaita Zone, (2017). Unpublished Annual Report.

Asalfew A. (2011), Demographic and Socio-economic Determinants of Youth Unemployment in Debere Birhan town, Master thesis, Addis Ababa University, Addis Ababa.

Central Statistical Agency (2012). Statistical Report on the 2012 Urban Employment, Unemployment Survey, 
Addis Ababa, Ethiopia.

Dejene T., J. Paul Mansingh and Warkaw L.(2016). Determinants of Youth Unemployment: The Case of Ambo Town, Ethiopia. International Journal of Economics and Business Management, 2016, 2(2), 162-169

ILO (2004). World Employment [Report] 2004-5. Employment Productivity and Poverty Reduction.

ILO (2012). The Youth Employment Crisis. Journal. Geneva.

ILO, (2017). Global Employment trends for Youth. Paths to better working future Global Employment Trends for Youth, 1- 115.

Labor Force Survey (2013), Statistical Report on the 2013 National Labour Force Survey, Central Statistical Agency, Addis Ababa, Ethiopia.

Maqbool, M.S., Abdul Sattar, T.M. and Bhalli, M.N. (2013). Determinants of Unemployment: Empirical Evidences from Pakistan. Pakistan Economic and Social Review, 51 (2):191-207.

Montgomery and Peck (1992). Introduction to Linear Regression Analysis (2 $2^{\text {nd }}$ ed). John Wiley \& Sons Inc. New York.

Mulugeta Sefinew Negatu (2013). A Study on Challenges and Prospects of Youth's Job Creation initiatives in the Amhara Region, Debre Berhan, Ethiopia.

Nganwa, P., Assefa, D., and Mbaka, P.(2015).The Nature and Determinants of Urban Youth Unemployment in Ethiopia. Public Policy and Administration Research Vol.5, No.3, 2015.ISSN 2224-5731 (Paper) ISSN:22250972 (Online).

Okojie. C. (2003). Employment Creation for Youth in Africa: The Gender Dimesion. Economic and Statistics University of Benin City, Nigeria.

Serneels. P. (2007). The Nature of Unemployment among Young Men in Urban Ethiopia. Review of Development Economics, 11(1), 170-186.

Shumet (2011) A Glimpse of Urban Youth Unemployment in Ethiopia, Ethiopian Journal of Development Research, vol.33, No.2.

Talent Youth Association (TaYa). (2013). Young people and the demographic dividend .Google (Accessed on July 2019)

Tegegne Gebeyaw (2011), Socio-Demographic Determinants of Urban Unemployment: The Case of Addis Ababa Ethiopian Journal of Development Research, Vol.33, No.2, October 2011

Yamane, T. (1967). Statistics, an Introductory Analysis, $2^{\text {nd }}$ Ed, New York. 